\title{
Effects of subacute ingestion of chlorogenic acids on sleep architecture and energy metabolism through activity of the autonomic nervous system: a randomised, placebo-controlled, double-blinded cross-over trial
}

\author{
Insung Park ${ }^{1}$, Ryuji Ochiai ${ }^{2}$, Hitomi Ogata ${ }^{1}$, Momoko Kayaba ${ }^{3}$, Sayaka Hari ${ }^{2}$, Masanobu Hibi ${ }^{2}$, \\ Yoshihisa Katsuragi $^{2}$, Makoto Satoh $^{3}$ and Kumpei Tokuyama ${ }^{1}$ \\ ${ }^{1}$ Graduate School of Comprehensive Human Science, Division of Sports Medicine, University of Tsukuba, 1-1-1 Tennodai, \\ Tsukuba, Ibaraki 305-8574, Japan \\ ${ }^{2}$ Health Care Food Research Laboratories, Kao Corporation, 2-1-3 Bunka, Sumida, Tokyo 131-8501, Japan \\ ${ }^{3}$ International Institute for Integrative Sleep Medicine, University of Tsukuba, 1-1-1 Tennodai, Tsukuba, Ibaraki \\ 305-8575, Japan
}

(Submitted 24 July 2016 - Final revision received 3 February 2017 - Accepted 17 February 2017 - First published online 17 April 2017)

\section{Abstract}

Chlorogenic acids (CGA) are the most abundant polyphenols in coffee. Continuous consumption of CGA reduces body fat and body weight. Since energy metabolism and sleep are controlled by common regulatory factors, consumption of CGA might modulate sleep. Lack of sleep has been identified as a risk factor for obesity, hypertension and type 2 diabetes. The aim of this study was to determine the effects of ingesting CGA over $5 \mathrm{~d}$ on energy metabolism and sleep quality in humans. A total of nine healthy subjects (four male and five female) completed a placebo-controlled, double-blinded, cross-over intervention study. Subjects consumed a test beverage containing 0 or 600 mg of CGA for $5 \mathrm{~d}$. On the fifth night, subjects stayed in a whole-room metabolic chamber to measure energy metabolism; sleep was evaluated using polysomnographic recording. It was found that CGA shortened sleep latency (9 (SEM 2) $v .16$ (SEM 4) min, $P<0 \cdot 05$ ) compared with the control, whereas no effect on sleep architecture, such as slow-wave sleep, rapid eye movement or waking after sleep onset, was observed. Indirect calorimetry revealed that consumption of CGA increased fat oxidation $(510$ (SEM 84$) \mathrm{kJ} / 8 \mathrm{~h}(122$ (SEM 20) $\mathrm{kcal} / 8 \mathrm{~h}) v$. 331 (SEM 79$) \mathrm{kJ} / 8 \mathrm{~h}$ (81 (SEM 19) kcal/8 h), $P<0.05)$ but did not affect energy expenditure during sleep. Consumption of CGA enhanced parasympathetic activity assessed from heart-rate variability during sleep (999 (SEM 77) $v .919$ (SEM 54), $P<0.05$ ). A period of 5-d CGA consumption significantly increased fat oxidation during sleep, suggesting that beverages containing CGA may be beneficial to reduce body fat and prevent obesity. Consumption of CGA shortened sleep latency and did not adversely affect sleep quality.

Key words: Chlorogenic acids: Energy metabolism: Sleep architecture: Autonomic nervous system

Coffee is one of the most widely consumed beverages throughout the world, and its origin dates back to the fifteenth century or earlier $^{(1)}$. Epidemiological studies have identified coffee consumption as a factor associated with reduced risks of type 2 diabetes $^{(2,3)}$, liver cirrhosis ${ }^{(4)}$, Alzheimer's disease ${ }^{(5)}$ and Parkinson's disease ${ }^{(6)}$. The coffee bean, and especially the green coffee bean, is known to be a rich source of biologically active compounds such as polyphenolic antioxidants including 5-caffeoylquinic acid (5-CQA) (formerly called 3-CQA or chlorogenic acid (CGA) $)^{(7)}$, 3-CQA, 4-CQA, 3,4-dicaffeoylquinic acid (3,4-diCQA), 3,5-diCQA, 4,5-diCQA, 3-feruloylquinic acid (3-FQA), 4-FQA, and 5-FQA, which consist of $\mathrm{CGA}^{(8,9)}$.

Recent human studies have shown that daily consumption of $340-600 \mathrm{mg} / \mathrm{d}$ of CGA (equivalent to one-two cups of coffee ${ }^{(10)}$ ) induced favourable effects on fat oxidation ${ }^{(11)}$ and lowered postprandial glucose ${ }^{(12)}$ and insulin resistance ${ }^{(13)}$ as well as had favourable effects on endothelial functions ${ }^{(14,15)}$ and mood enhancement ${ }^{(16)}$. Accumulating evidence has suggested that CGA exhibit many biological properties including antioxidant ${ }^{(17)}$, antiobesity $^{(18)}$, hypoglycaemic and hypolipidaemic effects ${ }^{(19)}$. Moreover, a recent study demonstrated that CGA exerts anti-amnesic activity via inhibition of acetylcholinesterase and malondialdehyde in the hippocampus and frontal cortex ${ }^{(20)}$. Foods and associated bioactive substances often affect multiple physiological functions, as exemplified by caffeine acting on the autonomic nervous system $^{(21)}$, energy metabolism ${ }^{(22,23)}$ and sleep ${ }^{(24)}$. Cross-talk between physiological functions exists within the body, and several lines of evidence suggest a link between sleep, the autonomic nervous system and energy metabolism ${ }^{(25)}$. Neurosubstances such as orexin, leptin and melatonin act on sleep and

Abbreviations: CGA, chlorogenic acids; CON, control; CQA, caffeoylquinic acid; diCQA, dicaffeoylquinic acid; E\%, energy percentage; FQA, feruloylquinic acid. 
wakefulness and on energy balance ${ }^{(26-28)}$. The effects of CGA ingestion on carbohydrate and fat metabolism warrant additional studies evaluating the effects of CGA ingestion on sleep, the lack of which has been identified as a risk factor for, amongst other conditions, obesity, hypertension and type 2 diabetes ${ }^{(29-31)}$. Metabolites of CGA potentiated pentobarbital-induced sleep by prolonging sleeping time and shortening sleep latency ${ }^{(32)}$, but the effects of consuming CGA on human sleep have not been studied.

The present study evaluated the effects of ingesting $600 \mathrm{mg}$ of CGA on sleep architecture, energy metabolism and autonomic nervous function in healthy male and female subjects. Simultaneous measurements of sleep architecture and respiratory analysis could provide new insights regarding which CGA exert possible sleep and energy metabolism improvements. To evaluate energy metabolism during sleep, whole-room indirect calorimetry was adopted, which provides a controlled environment in which energy metabolism can be continuously measured for a long period, including during sleep.

\section{Methods}

\section{Subjects}

In all, four healthy male subjects and five healthy female subjects with a mean age of 25.7 years and BMI of $21.8 \mathrm{~kg} / \mathrm{m}^{2}$ participated in this study. Subjects had normal sleeping profiles based on the Pittsburgh sleep quality index $(\leq 5)$. No subject had engaged in regular exercise more than twice a week or used any regular or temporary medication. Exclusion criteria for the subjects were a clinical diagnosis of sleep apnoea hypopnea syndrome, a medical or psychiatric condition, smokers and shift workers. Subjects who drank more than a bottle of alcohol $(350 \mathrm{ml})$ per day were also excluded from the study. For female subjects, those with a severe menstrual cycle problem and those who were pregnant were excluded. One female subject was excluded from the statistical analysis of energy metabolism because of mechanical trouble (unstable flow control of the metabolic chamber) during the trial with CGA. This study was conducted according to the guidelines laid down in the Declaration of Helsinki and all procedures involving human subjects were approved by the Ethics Committee of the University of Tsukuba. All subjects provided written informed consent before study commencement; the protocol was registered with Clinical Trials UMIN, ID no.: UMIN000022889.

\section{Protocol}

The present study was a placebo-controlled, double-blinded, cross-over intervention study. During each 5-d session, a test beverage containing 0 (control (CON)) or $600 \mathrm{mg}$ of CGA was consumed $10 \mathrm{~min}$ before bedtime and subjects were asked to refrain from ingesting beverages containing caffeine and alcohol. During the study, the subjects maintained their usual activities and dietary habits, which were confirmed by actigraphy recording and a daily diary. On days $3-5$, the subjects ingested specified meals for breakfast, lunch and dinner, which were provided by the study coordinators.
On the 5th day, subjects consumed lunch in the laboratory and stayed indoors. After consuming dinner, subjects entered the whole-room metabolic chamber and remained sedentary. Subjects went to bed at their usual bedtime and slept for $8 \mathrm{~h}$. Energy metabolism was measured for $16 \mathrm{~h}$ (from $3 \mathrm{~h}$ before bedtime on the 5 th day to $5 \mathrm{~h}$ after waking the next morning).

The meals provided in the laboratory were based on energy requirements estimated from the BMR equation ${ }^{(33)}$ with a physical activity level of $1 \cdot 3$. The meal composition (energy percentage $(\mathrm{E} \%)$ ) was $15 \mathrm{E} \%$ protein, $25 \mathrm{E} \%$ fat and $60 \mathrm{E} \%$ carbohydrates, and both groups received meals identical in quantity and composition. The energetic distribution was $30 \mathrm{E} \%$ for breakfast, $30 \mathrm{E} \%$ for lunch and $40 \mathrm{E} \%$ for dinner.

The experiment was preceded by an adaptation night in the metabolic chamber, during which the sensors and electrodes of the polysomnographic recording system were attached to the subjects. The two trials were separated by a washout period of 2-4 weeks, and studies with female subjects were performed during the same phase of the menstrual cycle; three female subjects were evaluated during the follicular phase and the other two female subjects were evaluated during the luteal phase.

\section{Beverages}

The CGA and placebo test beverages were prepared to be indistinguishable on the basis of appearance and flavour, and were canned $(100 \mathrm{ml})$. All CGA isomers are presented according to the IUPAC nomenclature ${ }^{(9)}$. The test beverage contained 0 or $600 \mathrm{mg}$ of CGA, which consisted of CQA (68\%), FQA (14\%) and diCQA (19\%) (Table 1). CGA were prepared from green coffee beans using hot water extraction followed by spray drying and girding. After activated carbon filtration, caffeine was not detected $(<0.5 \mathrm{~mm})$. The CGA composition in test beverages was measured by HPLC with a UV detector $(325 \mathrm{~nm})$. All peaks of the isomers were confirmed by LC-MS ${ }^{(34)}$. The standard, 5-CQA, was purchased from Sigma, and other standards, 3-CQA, 4-CQA, 3-FQA, 4-FQA, 5-FQA, 3,4-diCQA, diCQA and 3,5-diCQA, were obtained by repeated fractionations of green coffee bean extract (purity $>96 \%$, confirmed by LC-UV detection and ${ }^{1} \mathrm{H}-\mathrm{NMR}$ ) using preparative chromatography with an octa decyl silyl (ODS) column $^{(34)}$. Both beverages were caffeine-free, and the energy contents were $29 \mathrm{~kJ} / 100 \mathrm{ml}(7 \mathrm{kcal} / 100 \mathrm{ml})$ and $8 \mathrm{~kJ} / 100 \mathrm{ml}$ ( $2 \mathrm{kcal} / 100 \mathrm{ml})$ in the CGA and placebo beverages, respectively.

Table 1. Chlorogenic acid (CGA) compositions of the test beverages (mg/100 ml)

\begin{tabular}{lcr}
\hline & CON & CGA \\
\hline 3-CQA & 0.0 & $117 \cdot 5$ \\
4-CQA & 0.0 & $120 \cdot 6$ \\
5-CQA & 0.0 & $187 \cdot 1$ \\
3-FQA & 0.0 & $22 \cdot 7$ \\
4-FQA & 0.0 & 24.0 \\
5-FQA & 0.0 & 39.9 \\
3,5-diCQA & 0.0 & 28.4 \\
3,4-diCQA & 0.0 & $45 \cdot 7$ \\
4,5-diCQA & 0.0 & 43.7 \\
Total & 0.0 & 629.6 \\
\hline
\end{tabular}

CON, control; CQA, caffeoylquinic acid; FQA, feruloylquinic acid; diCQA, dicaffeoylquinic acid. 


\section{Sleep recording}

The recording system consisted of four electroencephalography derivations (C3-A2, C4-A1, O2-A1, and O1-A2), submental electromyography and bilateral electro-oculography using a PSG-1100 (Nihon Kohden). Sleep parameters were classified in 30-s intervals as wakefulness and stage 1, stage 2, slow-wave sleep (SWS), and rapid eye movement (REM) sleep according to the method developed by Rechtschaffen \& Kales ${ }^{(35)}$. In addition, total sleep time, sleep onset latency, REM sleep latency and sleep efficiency percentages were measured.

\section{Data analysis: spectral analysis of the electroencephalogram}

The C3-A2 electroencephalogram (EEG) recording was analysed using discrete fast Fourier transform techniques. The fast Fourier transform was conducted on an EEG record length of $5 \mathrm{~s}$ to obtain a frequency resolution of $0.2 \mathrm{~Hz}$. Each 5 -s segment of the EEG signal was first windowed with a Hanning tapering window before computing the power spectra. The spectral distribution was categorised into the following frequency bands: delta $(0.75-4.00 \mathrm{~Hz})$, theta $(4 \cdot 10-8.00 \mathrm{~Hz})$, alpha $(8 \cdot 10-12 \cdot 00 \mathrm{~Hz})$, sigma $(12 \cdot 10-14 \cdot 00 \mathrm{~Hz})$ and beta $(14 \cdot 10$ $30 \cdot 00 \mathrm{~Hz}$ ). The power content of the delta band for each $30-\mathrm{s}$ epoch of sleep was determined as the average power across the six 5-s segments of the EEG (expressed as $\left.\mu \mathrm{V}^{2}\right)^{(36)}$.

\section{Indirect calorimetry}

The airtight metabolic chamber measures $2.00 \times 3.45 \times 2.10 \mathrm{~m}$ (FHC-15S; Fuji Medical Science Co., Ltd), and was used from day 5 , $4 \mathrm{~h}$ before bedtime, to day $6,5 \mathrm{~h}$ after waking (total, $16 \mathrm{~h}$ ). Air in the chamber is pumped out at a rate of 80 litres $/ \mathrm{min}$. The temperature and relative humidity of incoming fresh air were controlled at $25^{\circ} \mathrm{C}$ and $55 \%$, respectively. The chamber was furnished with an adjustable hospital bed, desk, chair and toilet. Concentrations of $\mathrm{O}_{2}$ and carbon dioxide $\left(\mathrm{CO}_{2}\right)$ in outgoing air were measured with high precision by online process MS (VG Prima $\delta B$; Thermo Electron Co.). The precision of MS, defined as the standard deviation for continuous measurement of the calibrated gas mixture $\left(\mathrm{O}_{2}, 15 \%\right.$; $\mathrm{CO}_{2}, 5 \%$ ), was $0.0016 \%$ for $\mathrm{O}_{2}$ and $0.0011 \%$ for $\mathrm{CO}_{2}$. Every minute, $\mathrm{VO}_{2}$ and $\mathrm{CO}_{2}$ production $\left(\mathrm{VCO}_{2}\right)$ rates were calculated using an algorithm for improved transient response ${ }^{(37)}$. Oxidation of macronutrients and energy expenditure were calculated from $\mathrm{VO}_{2}, \mathrm{VCO}_{2}$ and urinary $\mathrm{N}$ excretion ${ }^{(38)}$. Rates of $\mathrm{N}$, an index of protein oxidation, were assumed to be constant during calorimetry:

$$
\begin{aligned}
& \text { Glucose oxidation }(\mathrm{g} / \mathrm{min})=4.55 \mathrm{VCO}_{2}(\text { litres } / \mathrm{min}) \\
& \left.-3 \cdot 21 \mathrm{VO}_{2} \text { (litres } / \mathrm{min}\right) \\
& -2 \cdot 87 \mathrm{~N}(\mathrm{~g} / \mathrm{min}) \text {. }
\end{aligned}
$$

Fat oxidation $(\mathrm{g} / \mathrm{min})=1.67 \mathrm{VO}_{2}($ litres $/ \mathrm{min})$

$$
-1.67 \mathrm{VCO}_{2} \text { (litres/min) }
$$$$
-1.92 \mathrm{~N}(\mathrm{~g} / \mathrm{min}) \text {. }
$$

Protein oxidation $(\mathrm{g} / \mathrm{min})=6 \cdot 25 \mathrm{~N}(\mathrm{~g} / \mathrm{min})$.
Once the rates of glucose, fat and protein oxidation had been computed, the total rate of energy production could be estimated by taking energetic equivalents of the three substrates into account. Conversion factors for energetic equivalents were $17 \cdot 15 \mathrm{~kJ} / \mathrm{g}(4 \cdot 10 \mathrm{kcal} / \mathrm{g})$ for protein $(107 \cdot 215 \mathrm{~kJ} / \mathrm{g}(25.625 \mathrm{kcal} / \mathrm{g})$ for urinary $\mathrm{N}), 15.65 \mathrm{~kJ} / \mathrm{g}(3.74 \mathrm{kcal} / \mathrm{g})$ for carbohydrates and $39.75 \mathrm{~kJ} / \mathrm{g}(9.50 \mathrm{kcal} / \mathrm{g})$ for $\mathrm{fat}^{(38)}$.

\section{Autonomic nervous system activity}

The R-R intervals of the electrocardiogram were continuously monitored using a telemetric heart-rate monitor (LX-3230, 207; Fukuda Denshi Co., Ltd) and the power spectrum of heart-rate variability was estimated using the maximum entropy method. The spectra measured were computed as amplitudes (i.e. areas under the power spectra) and are presented in $\mathrm{ms}^{2}$. Parasympathetic and sympathetic nervous system activities were estimated at a high frequency (HF; $0.15-0.4 \mathrm{~Hz}$ ) and as the power ratio of low frequency (LF; 0.04-0.15 Hz):high frequency (LF:HF), respectively ${ }^{(39)}$.

\section{Statistical analysis}

Results are expressed as means with their standard errors. Sample size was calculated on the basis of a power analysis using previous data. A study group of nine subjects was required for a power of $80 \%$ at a two-sided $\alpha$ of 0.05 . We performed a power analysis; the actual power was $>80 \%$ for each comparison. Paired $t$ tests were used to compare values of energy metabolism, sleep parameters and autonomic nervous system activity between the groups. The effects of CGA on the time course of autonomic nervous system activity were assessed by a two-way repeated measures ANOVA and a Bonferroni multiple comparison. Differences were considered significant when the error probability was $<0 \cdot 05$.

\section{Results}

Body weight, BMI and body fat did not change during the 5-d trial with control and CGA beverages (Table 2). Sleep architecture (lengths of stage 1 , stage 2, SWS, REM and wakefulness after sleep onset) was similar between the trials, except that sleep latency was shorter in trials with ingestion of CGA (Table 3). The time course of delta power, a quantitative index of SWS, was similar between the two trials, but those during the 1st hour of sleep during CGA trials tended to be higher than those during CON trials. A two-factor repeated measures ANOVA identified a significant interaction effect. The average delta power during the 1 st hour (CON: 29165 (SEM 5711) $\mu \mathrm{V}^{2} v$. CGA: 40758 (sem 5128) $\mu \mathrm{V}^{2}, P=0 \cdot 08$ ) seemed to be higher in the CGA trials than in the CON trials, but no statistically significant difference was found in multiple comparisons (Fig. 1).

The average sympathetic nervous system activity during $16 \mathrm{~h}$ of calorimetry was similar (CON: $2 \cdot 20$ (SEm 0.09) v. CGA: $2 \cdot 36$ (SEM 0.16)), but parasympathetic nervous system activity was enhanced by CGA consumption (CON: 919 (SEM 55) $\mathrm{ms}^{2} v$. CGA: 999 (SEM 78) $\mathrm{ms}^{2}, P<0 \cdot 05$ ). Visual inspection of the time course of autonomic nervous system activity suggests that parasympathetic activity and sympathetic activity increased during the second half 
Table 2. Anthropometric variables before and after ingesting either the chlorogenic acids (CGA) or placebo beverage for $5 \mathrm{~d}^{*}$ (Mean values with their standard errors)

\begin{tabular}{llllll}
\hline & \multicolumn{2}{c}{ Initial } & & \multicolumn{2}{c}{$5 \mathrm{~d}$} \\
\cline { 2 - 3 } \cline { 5 - 6 } & Mean & SEM & & Mean & SEM \\
\hline Body weight (kg) & & & & \\
Placebo group & 63.9 & 3.2 & & 64.0 & 3.2 \\
CGA group & 62.9 & 3.0 & 63.3 & 3.0 \\
BMl (kg/m ${ }^{2}$ ) & & & & \\
Placebo group & 21.8 & 0.5 & 22.1 & 0.5 \\
CGA group & 21.7 & 0.5 & 21.9 & 0.5 \\
Body fat (\%) & 24.6 & 2.3 & 25.1 & 2.2 \\
Placebo group & 23.8 & 2.1 & 24.6 & 2.2 \\
CGA group & & & & \\
\hline
\end{tabular}

${ }^{*}$ Mean values did not differ significantly between the groups.

Table 3. Sleep architecture

(Mean values with their standard errors)

\begin{tabular}{lrrrrrr}
\hline & \multicolumn{2}{c}{ CON } & & \multicolumn{2}{c}{ CGA } & \\
\cline { 2 - 3 } Parameters & Mean & SEM & & Mean & SEM & $P$ \\
\hline Total bedtime (min) & 480.0 & & 480.0 & & \\
Total sleep time (min) & 436.2 & 4.2 & & 444.2 & 3.9 & 0.268 \\
Wakefulness (min) & 27.9 & 4.3 & 26.7 & 4.0 & 0.840 \\
Sleep latency (min) & 15.6 & 4.5 & 8.7 & 2.7 & $0.043^{*}$ \\
Sleep efficiency (\%) & 90.9 & 0.9 & 92.5 & 0.8 & 0.275 \\
Stage 1 (min) & 58.4 & 7.0 & & 56.7 & 4.3 & 0.792 \\
Stage 2 (min) & 274.1 & 10.4 & 279.8 & 11.8 & 0.428 \\
SWS (min) & 15.7 & 5.6 & & 19.2 & 5.8 & 0.256 \\
REM sleep (min) & 87.8 & 7.0 & 88.3 & 6.7 & 0.956
\end{tabular}

CON, control; CGA, chlorogenic acids; SWS, slow-wave sleep; REM, rapid eye movement.

${ }^{*} P<0.05$.

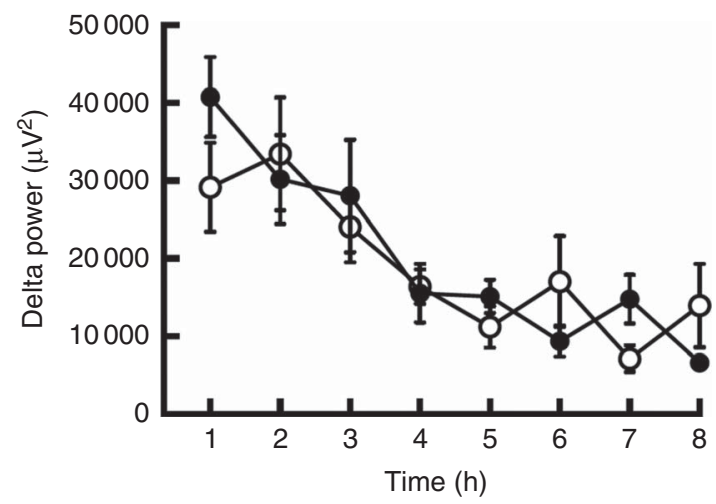

Fig. 1. The delta power of the sleep electroencephalogram after $5 \mathrm{~d}$ of ingestion of the chlorogenic acids beverage $(0)$ or placebo beverage $(O)$ is shown. Values are means ( $n 9$ per group), with standard errors.

of sleep and after awakening, respectively, by CGA consumption (Fig. 2). However, a statistically significant difference was not detected by a two-factor repeated measures ANOVA.

Fat oxidation during sleep $(8 \mathrm{~h})$ was higher in trials with chlorogenic ingestion than in control trials (Fig. 3). The difference in fat oxidation was also significant when entire 16-h calorimetry periods were compared (CON: 638.5 (SEM 118.4) kJ/ $16 \mathrm{~h}(152 \cdot 6$ (SEM 28.3) kcal/16 h) $v$. CGA: $958 \cdot 1$ (SEM 152.7) kJ/16 h
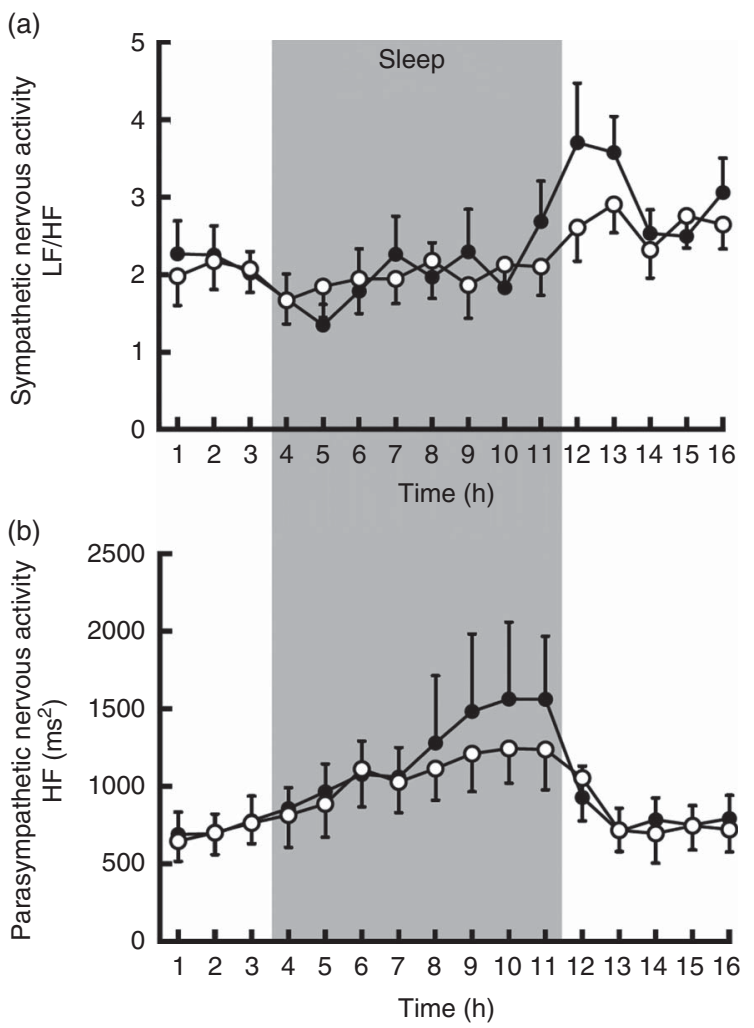

Fig. 2. Sympathetic (a) and parasympathetic (b) nervous system activities during calorimetry after $5 \mathrm{~d}$ of ingestion of the chlorogenic acids beverage (0) or placebo beverage $(O)$ are shown. Values are means ( $n 9$ per group), with standard errors. LF, low frequency, HF, high frequency.

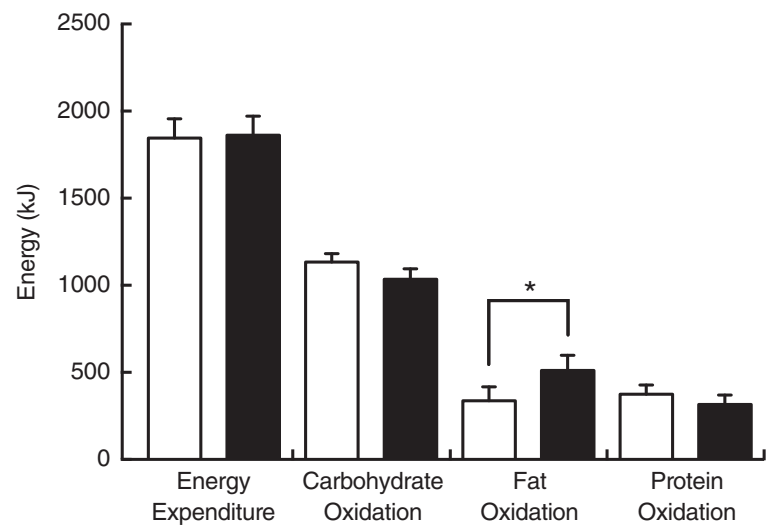

Fig. 3. Energy expenditure and substrate oxidation during sleep after $5 \mathrm{~d}$ of ingestion of the chlorogenic acids beverage $(\square)$ or placebo beverage ( $\square$ ). Values are means ( $n 8$ per group), with standard errors represented by vertical bars. ${ }^{\star} P<0.05$.

(229.0 (sEm 36.5) kcal/16 h), $P<0.05$ ). Energy expenditure was similar under both conditions, and the difference in carbohydrate oxidation was not statistically significant. Urinary $\mathrm{N}$ excretion as a marker of protein catabolism was similar between the two experimental conditions.

\section{Discussion}

In the present study, we assessed whether ingestion of beverages containing CGA for over $5 \mathrm{~d}$ had any effect on sleep, autonomic 
nervous system activity or energy metabolism in healthy humans. Our findings revealed that CGA shortened sleep latency as opposed to the controls, whereas no effect on sleep architecture such as SWS, REM or waking after sleep onset was observed. Indirect calorimetry revealed that consumption of CGA increased fat oxidation but did not affect energy expenditure during sleep. Consumption of CGA enhanced parasympathetic activity, which was assessed on the basis of heart-rate variability. These results support the possibility that beverages containing CGA possess beneficial effects to prevent obesity and improve sleep.

Fat oxidation during sleep was increased by consumption of CGA. An animal experiment reported an inhibitory effect of the green coffee bean extract, which is rich in CGA and its related compounds, on visceral fat accumulation and body weight gain in mice. CGA and its related compounds up-regulated carnitine palmitoyltransferase activity in the liver ${ }^{(40)}$. Using continuous and prolonged indirect calorimetry, the present study confirmed the findings of a previous report on use of indirect calorimetry for a short duration $(3.5 \mathrm{~h})$, which showed increased fat oxidation after ingestion of CGA $(359 \mathrm{mg})^{(41)}$. These indirect calorimetry findings are consistent with another human study reporting that daily consumption of coffee enriched with CGA for 12 weeks resulted in body weight reduction ${ }^{(42)}$.

The effect of CGA in stimulating fat oxidation during sleep was manifested without an adverse effect on sleep architecture, which is in contrast with the effects of sympathomimetics such as capsaicin, catechins and caffeine. Capsaicin, in addition to stimulating epinephrine secretion, acts as a transient receptor potential cation channel subfamily $\mathrm{V}$ member 1 agonist $^{(43)}$ and disturbs sleep via changes in body temperature. Caffeine, in addition to inhibiting the phosphodiesterase-induced degradation of intracellular cyclic AMP, acts as an adenosine $\mathrm{A}_{2 \mathrm{~A}}$ receptor antagonist and increases wakefulness ${ }^{(44)}$. Effects of catechins, which inhibit norepinephrine degradation, on sleep remain to be evaluated. A potential mediator of CGA that can shorten sleep latency is ferulic acid, which is a metabolite of CGA; ferulic acid also potentiates pentobarbital-induced sleep in mice by prolonging sleeping time and shortening sleep latency in a dosedependent manner ${ }^{(32)}$. At $1-2 \mathrm{~h}$ after the oral ingestion of CGA, they are metabolised via methylation and appear as ferulic acids in plasma ${ }^{(34,45)}$. Contrary to the present human study, sleep latency in rats was significantly increased by ingestion of CGA (CGA, $500 \mathrm{mg} / \mathrm{kg}$ and caffeic acid, $200 \mathrm{mg} / \mathrm{kg})^{(46)}$. The dose of CGA in the animal experiment was several orders of magnitude greater than that in the present human study. Human subjects, as opposed to experimental animals, were exposed to CGA via daily consumption of coffee and vegetables.

The function of the autonomic nervous system was also affected by ingestion of CGA through up-regulation of parasympathetic nervous system activity and a decrease in heart rate. An increase in parasympathetic nervous system activity may explain the antihypertensive effects of CGA, for which several mechanisms have been proposed: reduction of free radical production, scavenging free radicals, stimulation of $\mathrm{NO}$ production and inhibition of angiotensin-converting enzyme ${ }^{(47)}$. In addition to vasodilation effects in peripheral tissue, $\mathrm{NO}$ acts as a neuromodulator within the central and peripheral nervous systems, and modulates sympathetic and parasympathetic activities ${ }^{(48)}$. Close inspection of the time courses of sympathetic nervous system activity revealed the following. First, before and during the first $3 \mathrm{~h}$ of sleep, activities of the sympathetic and parasympathetic nervous systems were similar between the trials. The mechanism by which ingestion of CGA shortened sleep latency cannot be explained by the effect of chlorogenic ingestion on autonomic nervous system activity. Second, relative to that in the placebo-control trial, parasympathetic activity was higher during the second half of sleep, whereas sympathetic activity was higher after awakening in the morning in trials with ingestion of CGA. Thus, ingestion of CGA induced a greater decrease in parasympathetic activity and increase in sympathetic activity after awakening.

In conclusion, ingestion of CGA stimulated fat oxidation without an adverse effect on sleep architecture; rather, it shortened sleep latency. Ingestion of CGA increased parasympathetic activity during sleep, and the causal relation to its effects on sleep and fat oxidation remains to be evaluated. To generalise the present findings, an experiment with a larger sample size of obese and/or aged subjects should be performed.

\section{Acknowledgements}

We appreciate the technical support from Fuji Medical Science (Chiba, Japan) and Thermo Fisher Scientific (Winsford, UK).

I. P., M. H., M. S., and K. T. designed the study and edited the manuscript. S. H. provisioned study materials (test beverages). I. P. performed indirect calorimetry and M. K., H. O. and M. S. performed polysomnography (PSG) analyses of sleep. R. O. and Y. K. contributed to the 'Discussion' section and reviewed the manuscript.

M. H., R. O., S. H. and Y. K. are employees of the Kao Corporation. The authors declare that there are no conflicts of interest.

\section{References}

1. D'Amicis A \& Viani R (1993) The consumption of coffee. In Caffeine, Coffee and Health, pp. 1-16 [S Garattini, editor]. New York: Raven Press, Ltd.

2. Greenberg JA, Boozer CN \& Geliebter A (2006) Coffee, diabetes and weight control. Am J Clin Nutr 84, 682-693.

3. Van Dam RM \& Feskens EJ (2002) Coffee consumption and risk of type 2 diabetes mellitus. Lancet 360, 1477-1478.

4. Tverdal A \& Skurtveit S (2003) Coffee intake and mortality from liver cirrhosis. Ann Epidemiol 13, 419-423.

5. Eskelinen MH, Ngandu T, Tuomilehto J, et al. (2009) Midlife coffee and tea drinking and the risk of late-life dementia: a population-based CAIDE study. J Alzheimers Dis 16, 85-91.

6. Hernán MA, Takkouche B, Caamaño-Isorna F, et al. (2002) A meta-analysis of coffee drinking, cigarette smoking, and the risk of Parkinson's disease. Ann Neurol 52, 276-284.

7. Stalmach A, Steiling H, Williamson G, et al. (2010) Bioavailability of chlorogenic acids following acute ingestion of coffee by humans with an ileostomy. Arch Biochem Biophys 501, 98-105.

8. Clifford MN \& Wight J (1976) The measurement of feruloylquinic acids and caffeoylquinic acids in coffee beans. Development of the technique and its preliminary application to green coffee beans. J Sci Food Agric 27, 73-84. 
9. Anonymous (1976) IUPAC Commission on the Nomenclature of Organic Chemistry (CNOC) and IUPAC-IUB Commission on Biochemical Nomenclature (CBN). Nomenclature of cyclitols. Recommendations, 1973. Biochem J 153, 23-31.

10. Fukushima Y, Ohie T, Yonekawa Y, et al. (2009) Coffee and green tea as a large source of antioxidant polyphenols in the Japanese population. J Agric Food Chem 57, 1253-1259.

11. Soga S, Ota N \& Shimotoyodome A (2013) Stimulation of postprandial fat utilization in healthy humans by daily consumption of chlorogenic acids. Biosci Biotechnol Biochem 77, $1633-1636$.

12. Jokura H, Watanabe I, Umeda M, et al. (2015) Coffee polyphenol consumption improves postprandial hyperglycemia associated with impaired vascular endothelial function in healthy male adults. Nutr Res 35, 873-881.

13. Lecoultre V, Carrel G, Egli L, et al. (2014) Coffee consumption attenuates short-term fructose-induced liver insulin resistance in healthy men. Am J Clin Nutr 99, 268-275.

14. Ochiai R, Sugiura Y, Otsuka K, et al. (2015) Coffee bean polyphenols ameliorate postprandial endothelial dysfunction in healthy male adults. Int J Food Sci Nutr 66, 350-354.

15. Ochiai R, Sugiura Y, Shioya Y, et al. (2014) Coffee polyphenols improve peripheral endothelial function after glucose loading in healthy male adults. Nutr Res 34, 155-159.

16. Camfield DA, Silber BY, Scholey AB, et al. (2013) A randomised placebo-controlled trial to differentiate the acute cognitive and mood effects of chlorogenic acid from decaffeinated coffee. PLOS ONE 8, e82897.

17. Kono Y, Kobayashi K, Tagawa S, et al. (1997) Antioxidant activity of polyphenolics in diets. Rate constants of reactions of chlorogenic acid and caffeic acid with reactive species of oxygen and nitrogen. Biochim Biophys Acta 1335, 335-342.

18. Cho AS, Jeon SM, Kim MJ, et al. (2010) Chlorogenic acid exhibits anti-obesity property and improves lipid metabolism in high-fat diet-induced-obese mice. Food Chem Toxicol 48, 937-943.

19. Meng S, Cao J, Feng Q, et al. (2013) Roles of chlorogenic acid on regulating glucose and lipids metabolism: a review. Evid Based Complement Alternat Med 2013, 801457.

20. Kwon SH, Lee HK, Kim JA, et al. (2010) Neuroprotective effects of chlorogenic acid on scopolamine-induced amnesia via anti-acetylcholinesterase and anti-oxidative activities in mice. Eur J Pharmacol 649, 210-217.

21. Porciúncula LO, Sallaberry C, Mioranzza S, et al. (2013) The Janus face of caffeine. Neurochem Int 63, 594-609.

22. Arciero PJ, Gardner AW, Calles-Escandon J, et al. (1995) Effects of caffeine ingestion on NE kinetics, fat oxidation, and energy expenditure in younger and older men. Am J Physiol 268, E1192-E1198.

23. Bracco D, Ferrarra JM, Arnaud MJ, et al. (1995) Effects of caffeine on energy metabolism, heart rate, and methylxanthine metabolism in lean and obese women. Am J Physiol 269. E671-E678.

24. Júdice PB, Magalhães JP, Santos DA, et al. (2013) A moderate dose of caffeine ingestion does not change energy expenditure but decreases sleep time in physically active males: a double-blind randomized controlled trial. Appl Physiol Nutr Metab 38, 49-56.

25. Hirotsu C, Tufik S \& Andersen ML (2015) Interactions between sleep, stress, and metabolism: from physiological to pathological conditions. Sleep Sci 8, 143-152.

26. Nicolaidis S (2006) Metabolic mechanism of wakefulness (and hunger) and sleep (and satiety): role of adenosine triphosphate and hypocretin and other peptides. Metabolism 55, S24-S29.

27. Cipolla-Neto J, Amaral FG \& Afeche SC (2014) Melatonin, energy metabolism and obesity: a review. I Pineal Res 56, 371-381.
28. Sakurai T (2005) Roles of orexin/hypocretin in regulation of sleep/wakefulness and energy balance. Sleep Med Rev $\mathbf{9}$, 231-241.

29. Patel SR \& Hu FB (2008) Short sleep duration and weight gain: a systematic review. Obesity (Silver Spring) 16, 643-653

30. Cappuccio FP, Taggart FM, Kandala NB, et al. (2008) Meta-analysis of short sleep duration and obesity in children and adults. Sleep 31, 619-626.

31. Nielsen LS, Danielsen KV \& Sørensen TI (2011) Short sleep duration as a possible cause of obesity: critical analysis of the epidemiological evidence. Obes Rev 12, 78-92.

32. Tu Y, Cheng SX, Sun HT, et al. (2012) Ferulic acid potentiates pentobarbital-induced sleep via the serotonergic system. Neurosci Lett 525, 95-99.

33. Anon. (2010) Dietary Reference Intakes for Japanese. Tokyo: Ministry of Health Labour and Welfare of Japan.

34. Matsui Y, Nakamura S, Kondou N, et al. (2007) Liquid chromatography-electrospray ionization-tandem mass spectrometry for simultaneous analysis of chlorogenic acids and their metabolites in human plasma. J Chromatogr B Analyt Technol Biomed Life Sci 858, 96-105.

35. Rechtschaffen A \& Kales A (1968) A Manual of Standardized Terminology, Techniques and Scoring System for Sleep Stages of Human Subjects. Washington, DC: US Government Printing Office.

36. Zhang L, Samet J, Caffo B, et al. (2008) Power spectral analysis of EEG activity during sleep in cigarette smokers. Chest $\mathbf{1 3 3}$, 427-432.

37. Tokuyama K, Ogata H, Katayose Y, et al. (2009) Algorithm for transient response of whole body indirect calorimeter: deconvolution with a regularization parameter. I Appl Physiol (1985) 106, 640-650.

38. Ferrannini E (1988) The theoretical bases of indirect calorimetry: a review. Metabolism 37, 287-301.

39. Stein PK \& Kleiger RE (1999) Insights from the study of heart rate variability. Annu Rev Med 50, 249-261.

40. Shimoda H, Seki E \& Aitani M (2006) Inhibitory effect of green coffee bean extract on fat accumulation and bodyweight gain in mice. BMC Complement Altern Med 6, 9.

41. Noriyasu O, Satoko S, Takatoshi M, et al. (2010) Consumption of coffee polyphenols increases fat utilization in humans. J Health Sci 56, 745-751.

42. Thom E (2007) The effect of chlorogenic acid enriched coffee on glucose absorption in healthy volunteers and its effect on body mass when used long-term in overweight and obese people. J Int Med Res 35, 900-908.

43. Edwards SJ, Montgomery IM, Colquhoun EQ, et al. (1992) Spicy meal disturbs sleep: an effect of thermoregulation? Int J Psychophysiol 13, 97-100.

44. Huang ZL, Qu WM, Eguchi N, et al. (2005) Adenosine A2A, but not A1, receptors mediate the arousal effect of caffeine. Nat Neurosci 8, 858-859.

45. Renouf M, Guy PA, Marmet C, et al. (2010) Measurement of caffeic and ferulic acid equivalents in plasma after coffee consumption: small intestine and colon are key sites for coffee metabolism. Mol Nutr Food Res 54, 760-766.

46. Shinomiya K, Omichi J, Ohnishi R, et al. (2004) Effects of chlorogenic acid and its metabolites on the sleep-wakefulness cycle in rats. Eur J Pharmacol 504, 185-189.

47. Zhao Y, Wang J, Ballevre O, et al. (2012) Antihypertensive effects and mechanisms of chlorogenic acids. Hypertens Res 35, 370-374

48. Zanzinger J (1999) Role of nitric oxide in the neural control of cardiovascular function. Cardiovasc Res $\mathbf{4 3}$, 639-649. 